\title{
A Parametric Study on Dissimilar Metal Welding of Aluminum and Copper using Pulsed Fiber Laser
}

\section{Lanh Ngoc Trinh}

University of Nebraska-Lincoln

\section{Suman Chatterjee}

Kongju National University

Dongkyoung Lee ( $\nabla$ ldkkinka@kongju.ac.kr)

Kongju National University

\section{Research Article}

Keywords: Laser Welding, Dissimilar Metals, Aluminum, Copper, Microstructure, Mechanical Properties

Posted Date: September 22nd, 2021

DOl: https://doi.org/10.21203/rs.3.rs-907751/v1

License: (1) This work is licensed under a Creative Commons Attribution 4.0 International License. Read Full License 


\section{Abstract}

Joining dissimilar metals is critically challenging due to the difference in properties of the metals themselves which leads to the formation of brittle intermetallic compounds (IMCs). Aluminum (Al) and copper $(\mathrm{Cu})$ are well-known materials for electrical application as they attribute to various advantageous characteristics. In lithium-ion batteries, to obtain most of the features of the metals, combinations of these metals are highly recommended. However, with such high reflective metals and heat-sensitive characteristics in the battery, the joint of these metals needs to be processed with an advanced method. In this study, a pulsed fiber laser source that suits to process for heat-sensitive components is utilized to weld two overlap configurations of $\mathrm{Al} / \mathrm{Cu}$ and $\mathrm{Cu} / \mathrm{Al}$, separately. Different ranges of laser power are designated for each welding configuration separately. Thus, the quality of the two welds is evaluated in terms of microstructure and mechanical properties. Consequently, it is found that the growth of IMCs with dendritic structure towards the Al side is observed in both cases. Moreover, the weld of $\mathrm{Al} / \mathrm{Cu}$ shows a better connection strength as well as fewer imperfections than the weld of $\mathrm{Cu} / \mathrm{Al}$.

\section{Introduction}

Being a crucial part of electronic devices and electric vehicles, lithium-ion batteries have been attracting global attention recently [1]-[3]. To meet up global desire, manufacturers now are making great efforts to achieve a better battery with various features in safety, durability, power performance, etc. However, during the production of lithium-ion batteries, multiple welding processes are required [4]. As the welded connection in the battery would have a significant impact on the electrical flow which in turn affects the battery performance between connected parts, the weld would be one of the key factors to improve the battery performance.

In the battery industry, aluminum (Al) and copper $(\mathrm{Cu})$ are the materials with the most consumption as they feature high conductivity. Besides, Al is also well known for a lightweight and easy forming material, while $\mathrm{Cu}$ owns great tensile strength. Therefore, the combination of these materials provides great benefits to improve the performance of the batteries. However, joining for these dissimilar metals originally makes special demand to the joining technique since the common unforeseen formation of Intermetallic Compounds (IMCs) [5]-[8]. The formation of IMCs in the dissimilar weld of Al and Cu occurs due to the low solubility of the metals. According to the phase diagram of $\mathrm{Al}$ and $\mathrm{Cu}$, as shown in Fig. 1, the maximum solubility of $\mathrm{Cu}$ in $\mathrm{Al}$ is $2.5 \%$ and $\mathrm{Al}$ in $\mathrm{Cu}$ is about $19.7 \%$. Therefore, the interdiffusion of the metals during welding easily leads to the formation of the brittle Al-Cu IMCs. These IMCs are generally brittle [9]. Therefore, the growth of IMCs results in significant degradation of the weld properties and the formation of several weld defects such as porosities and cracks [10]-[13]. Moreover, the increase of the IMCs thickness induces a significant increase in contact resistance of Al-Cu joints [14]. Besides, the metals show very different physical and metallurgical properties such as density, melting point, boiling point, and thermal conductivity shown in Table 1. 
Over the past years, many researchers have been proposed different joining methods for Al-Cu joint including solid-state and fusion welding. In particular, friction-stir welding has been attempted to joint dissimilar metals of Al and Cu by many researchers [15]-[17]. Meanwhile, scholars also reported several critical issues attributed to the friction-stir welding such as tool matters [18], failures at the interface, or nugget zone during mechanical testing [19], [20]. Next, ultrasonic spot welding which has the merit of less energy consumption and relatively short weld time has been utilized to weld $\mathrm{Al}$ and $\mathrm{Cu}$ [21]-[24]. Nevertheless, the dissimilar weld of $\mathrm{Al}$ and $\mathrm{Cu}$ conducted by ultrasonic spot welding also revealed several issues. As the welding method also require welding tool, tool matters such as tool wear and tool-material contact will adversely affect the weld quality [25]. The feasibility of dissimilar joining for $\mathrm{Al}$ and $\mathrm{Cu}$ using resistance spot welding was also investigated [26]. However, studies also pointed out limitations of the weld with resistance spot welding including materials, welding configuration, and welding tools. Therefore, it is necessary to develop a tool-free welding method. Fortunately, researchers and manufacturers have recently been employing the use of laser beam in manufacturing processes including welding for various materials. Laser beam welding (LBW) attributes with unique features such as non-contact processing, high energy intensity, and ease to control energy input so that LBW has successfully joined both similar and dissimilar thermal plastic materials [27]-[29]. Furthermore, LBW for dissimilar metals of $\mathrm{Al}$ and $\mathrm{Cu}$ has been investigating by many researchers. For instance, Xue et al. [30] used ANSYS FLUENT to create a 3D finite volume simulation for the molten pool behavior for the weld of dissimilar metals of Al and Cu using a continuous wave laser source. The study concluded that an extensive interdiffusion of $\mathrm{Cu}$ and $\mathrm{Al}$ took place in the molten state with the given welding condition. Thus, different varieties of Al-Cu IMCs were formed in the weld. Meanwhile, Fetzer et al. [31] and Dimatteo et al. [32] have developed the laser welding for $\mathrm{Al}$ and $\mathrm{Cu}$ with continuous-wave laser source using beam oscillation technique. Both studies have reported that the weld with beam oscillation techniques has been significantly improved, and the element mixing in the fused zone is enhanced. Moreover, the penetration depth of the weld could be controlled by the adjustment of the oscillation amplitude. To provide more options in laser welding for Al and Cu, Wang et al. [33] described a study on an advanced welding technique in which he utilized a laser beam with a focal spot size of $6000 \mu \mathrm{m}$ to create laser shock welding. The study has proved the feasibility of laser shocking in joining the dissimilar metals of Al and $\mathrm{Cu}$ and achieved a nearly flat interface in the weld. Moreover, laser welding for Al and Cu with the use of the laser with a focal spot size of $800 \mu \mathrm{m}$ and $635 \mu \mathrm{m}$ was also performed by Zuo et al. [10] and Lerra et al [34], respectively. In summary, it can be seen that most studies are focusing on the use of laser beam with the focal spot size of hundreds of micrometers for laser welding of the dissimilar metals. Dissimilar metals of $\mathrm{Al}$ and $\mathrm{Cu}$ joint using a pulsed wave laser and focused spot size is less being investigated. Using pulsed wave laser produces a peak power for each pulse, thus the weld can obtain a deep penetration with shorter interaction time. As short interaction time is required, the pulsed wave laser is suitable for heat-sensitive components as well as reflective materials (e.g., Al and $\mathrm{Cu}$ ).

Therefore, we aim to investigate the weld of dissimilar of $\mathrm{Al}$ and $\mathrm{Cu}$ using a pulsed wave laser beam with a focused spot size $(40 \mu \mathrm{m})$. Moreover, two opposite lap welding configurations (Al/Cu and $\mathrm{Cu} / \mathrm{Al}$ ) will be performed and compared. The weld will be analyzed in terms of microstructure characteristics and 
mechanical properties. The microstructure of the weld will be revealed mainly through cross-section observation, while mechanical properties of the weld will be evaluated with hardness distribution and mechanical strength.

Table 1

Physical and mechanical properties of $\mathrm{Al}$ and $\mathrm{Cu}$ [35].

\begin{tabular}{|c|c|c|c|c|c|c|}
\hline Material & $\begin{array}{l}\text { Density } \\
\left(\mathrm{g} / \mathrm{cm}^{3}\right. \\
)^{3}\end{array}$ & $\begin{array}{l}\text { Melting } \\
\text { point } \\
\left({ }^{\circ} \mathrm{C}\right)\end{array}$ & $\begin{array}{l}\text { Boiling } \\
\text { point } \\
\left({ }^{\circ} \mathrm{C}\right)\end{array}$ & $\begin{array}{l}\text { Thermal } \\
\text { conductivity } \\
(\mathrm{W} / \mathrm{m} \mathrm{K})\end{array}$ & $\begin{array}{l}\text { Modulus of } \\
\text { Elasticity } \\
\text { (GPa) }\end{array}$ & $\begin{array}{l}\text { Poisson's } \\
\text { Ratio }\end{array}$ \\
\hline Aluminum & 2.7 & 660 & 2470 & 205 & 68 & 0.36 \\
\hline Copper & 8.96 & 1085 & 2562 & 385 & 0.33 & 0.35 \\
\hline
\end{tabular}

\section{Experiment}

Figure 2 shows the schematic of the experimental setup. The laser source used in the experiment is an ytterbium pulsed fiber laser (IPG-YLPM, IPG photonics, Southbridge, Massachusetts USA). The specification of the laser source is indicated in Table 2. The welding experiment of $\mathrm{Al}$ and $\mathrm{Cu}$ are conducted in two overlap configurations of $\mathrm{Al} / \mathrm{Cu}$ and $\mathrm{Cu} / \mathrm{Al}$. The laser power for the experiment varies according to the welding configuration. Firstly, preliminary experiments are performed on both welding configurations. After the preliminary experiments, the variation of the laser power for the investigation is set. The selection of laser power range for each welding configuration is done based on the weldability. The laser power range is from the lowest laser power required to form a joint between materials. The variation of the laser power for each weld are shown in Table 3. Besides, the wobbling technique is applied in this study as it has been proved to enhance the weld quality in literature [31], [32]. The thin sheets of Al and copper having thickness of $0.27 \sim 0.3 \mathrm{~mm}$ has been employed as welding specimens in the experiment. The welds are conducted in overlap configuration with the dimension shown in Fig. $\mathbf{2 b}$ ).

The observation of the welded specimen is firstly implemented with a Dino-lite microscope for top and bottom view. Next, Scanning Electron Microscope (SEM) is employed for further observing the microstructure of the weld in cross-section view. To identify mechanical properties, hardness in the weld zone is measured with Vickers hardness measurement, while a shear strength test is applied for the welded specimen to evaluate the mechanical strength of the weld. 
Table 2

Specifications of the laser source

\begin{tabular}{|ll|}
\hline Laser type & Pulsed fiber laser \\
\hline Maximum laser power & $300 \mathrm{~W}$ \\
\hline Wavelength & $1064 \mathrm{~nm}$ \\
\hline Pulse duration & $20 \mathrm{~ns}$ \\
\hline Spot size & $40 \mu \mathrm{m}$ \\
\hline Frequency & $2000 \mathrm{kHz}$ \\
\hline Welding speed & $5 \mathrm{~mm} / \mathrm{s}$ \\
\hline
\end{tabular}

Table 3

Laser power and wobbling specification

\begin{tabular}{|llll|}
\hline Configuration & Laser power range $(\mathrm{W})$ & Wobbling & \\
\cline { 3 - 4 } & & Amplitude $(\mathrm{mm})$ & Frequency $(\mathrm{kHz})$ \\
\hline $\mathrm{Al} / \mathrm{Cu}$ & $80-160$ & 0.5 & 100 \\
\hline $\mathrm{Cu} / \mathrm{Al}$ & $180-260$ & & \\
\hline
\end{tabular}

\section{Result And Discussion}

\subsection{Microstructure}

The morphology of the top and bottom surface of the weld in both configurations are observed and shown in Fig. 3. In the weld of $\mathrm{Al} / \mathrm{Cu}$, the top surface reveals a clean weld surface without visible spatters on the weld surface. In contrast, a visible heat-affected zone tends to enlarge at the end of the welding line in the weld of $\mathrm{Cu} / \mathrm{Al}$. From the bottom view, heat-affected evidence is visible from the laser power of $120 \mathrm{~W}$ when $\mathrm{Al}$ is on top of $\mathrm{Cu}$. Meanwhile, in the weld of $\mathrm{Cu} / \mathrm{Al}$, full penetration can be observed from the laser power of $180 \mathrm{~W}$. Overall, with the growth of the visible defect on the bottom view as the laser power increases, one can be withdrawn that the penetration increases with increasing laser power.

Figure 4 exhibits the observation of cross-section view in both welds of $\mathrm{Al} / \mathrm{Cu}$ and $\mathrm{Cu} / \mathrm{Al}$. In the case of $\mathrm{Al} / \mathrm{Cu}$, the observation result demonstrates an increase of penetration depth when laser power increases. Moreover, dense porosities are observed at the laser power of $140 \mathrm{~W}$ and $160 \mathrm{~W}$ mainly in the upper material (Al). At the laser power of $140 \mathrm{~W}$, porosities are found to lie on the interface line of the welded materials, while pores are formed around visible cracks initiated from the Al material when laser power of $160 \mathrm{~W}$ is used. In the case of $\mathrm{Cu} / \mathrm{Al}$ weld, the cross-section reveals fluctuated weld surface as well as loss 
of material in the weld zone. As the laser power increases, the loss of material rises. A reliable explanation for this is the high reflectance of $\mathrm{Cu}[36]$ together with high energy input (i.e., laser power). Besides, porosities are also detected mainly in the Al side.

The microstructure of the interface in the weld of $\mathrm{Al} / \mathrm{Cu}$ and $\mathrm{Cu} / \mathrm{Al}$ is shown in Fig. $\mathbf{5}$. In both welds, the dendritic structure is observed to form and expand towards the Al side. The chemical composition of the dendritic structure has been examined and shown in Table 4. The result reveals that the dendritic structure reveals the structure for the $\mathrm{IMCs}_{\mathrm{M}}$ of $\mathrm{Al}_{2} \mathrm{Cu}$. Meanwhile, a thicker layer of dendritic structure can be detected in the case of $\mathrm{Al}$ on top in comparison with the weld of $\mathrm{Cu} / \mathrm{Al}$. To understand the behaviour of microstructures in the weld zone Kirkendall effect has been considered [37]. A reliable explanation for the expansion of dendritic structure into the Al side relates to the phenomenon of the Kirkendall effect which is demonstrated by Smigelskas and Kirkendall [37]. The Kirkendall effect expresses the motion of the interface between two metals due to the difference in the diffusion rate of the metal atoms. The illustration for the effect is indicated in Fig. 6. During the welding process, the atoms of $\mathrm{Al}$ and $\mathrm{Cu}$ start to diffuse to each other. The diffusion rate of $\mathrm{Cu}$ is generally five times higher than that of $\mathrm{Al}$, and the diffusion rate of $\mathrm{Cu}$ is linearly proportional to temperature shown in Fig. 6(a) [38]. The interdiffusion of Al and $\mathrm{Cu}$ leads to the formation of Al-Cu intermetallic compounds shown in Fig. $\mathbf{6}$ (b). Together with the low diffusion rate of Al, the spread of IMCs will tend to be on the Al side shown in Fig. 6(c).

\section{Table 4}

Chemical composition on the cross-section of the points in Figure 5.

\begin{tabular}{|lccl|}
\hline Point & Al (at\%) & $\mathrm{Cu}($ at\%) & Possible phase \\
\hline 1 & 61.16 & 38.84 & $\mathrm{Al}_{2} \mathrm{Cu}$ \\
\hline 2 & 83.88 & 16.12 & $\mathrm{Al}+\mathrm{IMCs}$ \\
\hline 3 & 87.52 & 12.48 & $\mathrm{Al}+\mathrm{IMCs}$ \\
\hline 4 & 69.86 & 30.14 & $\mathrm{Al}_{2} \mathrm{Cu}$ \\
\hline 6 & 83.65 & 16.35 & $\mathrm{Al}+\mathrm{IMCs}$ \\
\hline
\end{tabular}

\subsection{Mechanical properties}

\section{a. Hardness profile}

Vickers hardness measurement is conducted vertically in the cross-section of the weld from the upper material to the lower material. The hardness measurement of the weld of $\mathrm{Al} / \mathrm{Cu}$ is shown in Fig. 7. Within the upper material (Al) in the weld configuration of $\mathrm{Al} / \mathrm{Cu}$, the hardness increases as the distance is close to interface. Meanwhile, the hardness distribution in the weld with the laser power of $80 \mathrm{~W}$ remains 
similar to the base materials (Al: $60 \mathrm{HV}, \mathrm{Cu}: 117 \mathrm{HV}$ ). At the laser power of $100 \mathrm{~W}$, a sharp increase of hardness takes place at the interface. Meanwhile, a significant rise in hardness happens at the distance of $50 \mu \mathrm{m}$ from the interface when the laser powers of $120 \mathrm{~W}, 140 \mathrm{~W}$, and $160 \mathrm{~W}$ are used. In other words, the peak hardness at each laser power shifts towards the Al side when the laser power increases. Furthermore, with the increment of the laser power, the peak hardness of individual laser power rises. In particular, the maximum hardness at the laser power of $100 \mathrm{~W}$ and $120 \mathrm{~W}$ are $625.9 \mathrm{HV}$ and $880 \mathrm{HV}$, respectively. Meanwhile, the peak hardness obtained at the laser power of $140 \mathrm{~W}$ is $890 \mathrm{HV}$ and at the laser power of $160 \mathrm{~W}$ is $995.7 \mathrm{HV}$. In the lower material $(\mathrm{Cu})$, the hardness decreases significantly at the distance of $50 \mu \mathrm{m}$ and $100 \mu \mathrm{m}$ from the interface. From the distance of $150 \mu \mathrm{m}$ towards the bottom, there is an insignificant variation of the hardness among different laser powers.

Figure 8 indicates the hardness profile of the weld with $\mathrm{Cu}$ on top of Al. Overall, the material surrounding the interface is reported with high hardness. Within the upper material $(\mathrm{Cu})$ at all laser powers, hardness increases as the distance is close to the interface. Peak hardness values at the laser power of $180 \mathrm{~W}$ and $200 \mathrm{~W}$ are measured at the interface of $\mathrm{Al}$ and $\mathrm{Cu}$. Meanwhile, the maximum hardness values at the laser power of $220 \mathrm{~W}$ and $240 \mathrm{~W}$ are detected in the Al side at the distance of $50 \mu \mathrm{m}$ and $100 \mu \mathrm{m}$ from the interface, respectively. On the Al side, it is noticed that the high hardness zone expands together with the increase of the laser power. In particular, at the laser power of $200 \mathrm{~W}$, the material with the hardness exceeding $300 \mathrm{HV}$ remains till the distance of $50 \mu \mathrm{m}$ from the interface. In comparison, at the laser power of $220 \mathrm{~W}$ and $240 \mathrm{~W}$, the high hardness zone remains within the distances of $200 \mu \mathrm{m}$ and $250 \mu \mathrm{m}$ from the interface, respectively.

\section{b. Mechanical strength}

The mechanical strength of the weld is evaluated by the shear strength test. Figure 9 expresses the ultimate loading forces of each weld according to laser powers. It is clear that the weld of $\mathrm{Al} / \mathrm{Cu}$ achieves higher weld strength than the weld of $\mathrm{Cu} / \mathrm{Al}$. Furthermore, an optimal laser power at which the maximum mechanical strength can be achieved is also recognized in both cases. In particular, in the weld of $\mathrm{Al} / \mathrm{Cu}$, the weld attains the average shear loading force of $246.82 \mathrm{~N}$ at the laser power of $80 \mathrm{~W}$. The low strength of the weld with the laser power of $80 \mathrm{~W}$ can be explained by the lack of penetration in the weld. The ultimate loading force of $297.59 \mathrm{~N}$ which is higher than the shear strength of base $\mathrm{Al}(260 \mathrm{~N})$ and lower than the strength of base $\mathrm{Cu}(490 \mathrm{~N})$ is recorded at the weld with the laser power of $100 \mathrm{~W}$. As for laser power of $120 \mathrm{~W}, 140 \mathrm{~W}$, and $160 \mathrm{~W}$, the recorded loading forces declines, respectively. The downturn of the shear strength of the weld when the laser power increase is related to the increase of the IMCs formation in the weld. As shown in Fig. 10, the intermixture of $\mathrm{Al}$ and $\mathrm{Cu}$ in the interface of the weld $\mathrm{Al} / \mathrm{Cu}$ increases with the increase of laser power.

When the weld is conducted with the configuration of $\mathrm{Cu} / \mathrm{Al}$, the shear strength of the weld is obtained with a similar tendency as in the weld of $\mathrm{Al} / \mathrm{Cu}$ with the given laser power range. At the laser power of 180 $\mathrm{W}$, the average ultimate loading force recorded is $64.85 \mathrm{~N}$. When the weld is conducted with the laser 
power of $200 \mathrm{~W}$, the average strength reaches $83.8 \mathrm{~N}$. Afterward, the average of the ultimate loading force reduces as the laser power increases. The lowest strength of the weld is found at the laser power of 260 W with the average loads that the weld can endure is $57.64 \mathrm{~N}$. It is important to note that the explanation for the reduction of the weld strength in $\mathrm{Cu} / \mathrm{Al}$ welds relies on the loss of the weld metal in the weld zone due to evaporation. As shown in Fig. 4, the loss of the weld metal in the cross-section view increases as the laser power increases. The loss of the weld metal will weaken the connection strength.

Moreover, the fracture behavior of $\mathrm{Al} / \mathrm{Cu}$ and $\mathrm{Cu} / \mathrm{Al}$ welds are significantly different. Figure 11 demonstrates the shear strength test result for the weld of $\mathrm{Al} / \mathrm{Cu}$ and $\mathrm{Cu} / \mathrm{Al}$ with the presence of elongation. Overall, the weld of $\mathrm{Al} / \mathrm{Cu}$ results in a longer elongation before it fractures than the weld of $\mathrm{Cu} / \mathrm{Al}$. Moreover, the fracture of most of the weld in the configuration of $\mathrm{Cu} / \mathrm{Al}$ happens at the ultimate load points, while there is elongation after the ultimate load in the case of $\mathrm{Al} / \mathrm{Cu}$ weld. In short, the weld of $\mathrm{Al} / \mathrm{Cu}$ is more ductile than the weld of $\mathrm{Cu} / \mathrm{Al}$.

\section{Conclusion}

In this study, the weld of dissimilar metals of $\mathrm{Al}$ and $\mathrm{Cu}$ is performed with the use of a pulsed fiber laser. Using the pulsed wave laser provides many benefits for joining heat-sensitive components due to concentrated laser beam and short pulse duration which leads to less interaction time. In the present study, the welding result is evaluated through microstructure observation and mechanical behavior. Overall, the weld of $\mathrm{Al} / \mathrm{Cu}$ required less laser energy to be welded (e.g., laser power). The weld with $\mathrm{Al}$ on top also reveals significant beneficial characteristics in comparison with the weld of $\mathrm{Cu} / \mathrm{Al}$. Through the study, several considerations can be concluded as follows:

- The formation of $\mathrm{Al}_{2} \mathrm{Cu}$ with dendritic structure expands towards $\mathrm{Al}$ in both cases of $\mathrm{Al}$ on top and $\mathrm{Cu}$ on top. This occurs due to the difference in the diffusion rate of the base metals explained by the Kirkendall effect.

- The weld metal on the aluminum side is obtained with higher hardness than that on the $\mathrm{Cu}$ side. $\mathrm{Cu} / \mathrm{Al}$ weld produces a deeper extension of high-hardness weld metal in $\mathrm{Al}$ side than $\mathrm{Al} / \mathrm{Cu}$ weld.

- With the given welding condition, the highest shear strength of the weld $\mathrm{Al} / \mathrm{Cu}$ and $\mathrm{Cu} / \mathrm{Al}$ are obtained at the laser power of $100 \mathrm{~W}$ and $200 \mathrm{~W}$, respectively. Meanwhile, Al/Cu weld has higher strength and more ductile than the weld of $\mathrm{Cu} / \mathrm{Al}$.

Overall, a clear comparison between two welding configurations for dissimilar metals of Al and Cu has been clarified in the study. However, to have a further understanding of the interaction of the pulsed fiber laser to $\mathrm{Al}$ and $\mathrm{Cu}$, another study will be conducted aiming at investigating the microstructure characteristics of the joints. Thus, the relationship between the microstructure of the joint and its effect on mechanical behavior can be established.

\section{Declarations}




\section{Acknowledgment}

The research described herein was sponsored by the National Research Foundation of Korea (NRF) grant funded by the Korean government (MSIP; Ministry of Science, ICT, and Future Planning) (No. 2019R1A2C1089644) and by the KOREA INNOVATION FOUNDATION grant funded by the Korea government (MSIP) (No. 2020-DD-SB-0159).

The opinions expressed in this paper are those of the authors and do not necessarily reflect the views of the sponsors.

\section{References}

1. Yuan, X. \& Wu, J. "Research on the Development of pure electric vehicle power battery Technology based on patent analysis,"IOP Conf. Ser. Earth Environ. Sci., vol. 615, no. 1, 2020.

2. Manthiram, A. An Outlook on Lithium lon Battery Technology. ACS Cent. Sci, 3 (no. 10), 1063-1069 (2017).

3. Zubi, G., Dufo-López, R., Carvalho, M. \& Pasaoglu, G. "The lithium-ion battery: State of the art and future perspectives," Renew. Sustain. Energy Rev., vol. 89, no. October 2017, pp. 292-308, 2018.

4. Lee, S. S. et al. "Joining technologies for automotive Li-ion battery manufacturing - A REVIEW," pp.1-9, 2016.

5. Wei, Y., Li, J., Xiong, J. \& Zhang, F. Investigation of interdiffusion and intermetallic compounds in AlCu joint produced by continuous drive friction welding. Eng. Sci. Technol. an Int. J, 19 (no. 1), 90-95 (2016).

6. Hannech, E. B., Lamoudi, N., Benslim, N. \& Makhloufi, B. Intermetallic formation in the aluminumcopper system. Surf. Rev. Lett, 10 (no. 4), 677-683 (2003).

7. Abbasi, M., Karimi Taheri, A. \& Salehi, M. T. Growth rate of intermetallic compounds in Al/Cu bimetal produced by cold roll welding process. J. Alloys Compd, 319 (no. 1-2), 233-241 (2001).

8. Cheepu, M. \& Susila, P. Growth Rate of Intermetallics in Aluminum to Copper Dissimilar Welding. Trans. Indian Inst. Met, 73 (no. 6), 1509-1514 (2020).

9. Hug, E. \& Bellido, N. Brittleness study of intermetallic ( $\mathrm{Cu}, \mathrm{Al})$ layers in copper-clad aluminium thin wires. Mater. Sci. Eng. A, 528, no. 22-23 (2011).

10. Zuo, D., Hu, S., Shen, J. \& Xue, Z. Intermediate layer characterization and fracture behavior of laserwelded copper/aluminum metal joints. Mater. Des, 58, 357-362 (2014).

11. Weigl, M. \& Schmidt, M. "Modulated laser spot welding of dissimilar copper-aluminium connections," Int. Conf. Multi-Material Micro Manuf. 4M/International Conf. Micro Manuf. ICOMM, pp. 211-214 2009.

12. Kalaiselvan, K. \& Elango, A. Studies of Interfacial Microstructure and Mechanical Properties on Dissimilar Sheet Metal Combination Joints Using Laser Beam Welding. Int. J. Mech. Mechatronics Eng, 8 (no. 11), 1881-1888 (2014). 
13. Lee, W. B., Bang, K. S. \& Jung, S. B. Effects of intermetallic compound on the electrical and mechanical properties of friction welded Cu/Al bimetallic joints during annealing. J. Alloys Compd, 390 , no. 1-2 (2005).

14. Braunovid, M. \& Aleksandrov, N. "Intermetallic compounds at aluminum-to-copper and copper-to-tin electrical interfaces,” Electr. Contacts, Proc. Annu. Holm Conf. Electr. Contacts, vol. 1992-Octob, no. November 1992, pp. 25-34 1992.

15. Akinlabi, E. T., Andrews, A. \& Akinlabi, S. A. Effects of processing parameters on corrosion properties of dissimilar friction stir welds of aluminium and copper. Trans. Nonferrous Met. Soc. China (English Ed, 24 (no. 5), 1323-1330 (2014).

16. Xue, P., Ni, D. R., Wang, D., Xiao, B. L. \& Ma, Z. Y. Effect of friction stir welding parameters on the microstructure and mechanical properties of the dissimilar Al-Cu joints. Mater. Sci. Eng. A, 528, no. 13-14 (2011).

17. Ouyang, J., Yarrapareddy, E. \& Kovacevic, R. Microstructural evolution in the friction stir welded 6061 aluminum alloy (T6-temper condition) to copper. J. Mater. Process. Technol, 172 (no. 1), 110-122 (2006).

18. Mehta, K. P. \& Badheka, V. J. A review on dissimilar friction stir welding of copper to aluminum: Process, properties, and variants. Mater. Manuf. Process, 31 (no. 3), 233-254 (2016).

19. Ouyang, J. H. \& Kovacevic, R. Material flow and microstructure in the friction stir butt welds of the same and dissimilar aluminum alloys. J. Mater. Eng. Perform, 11 (no. 1), 51-63 (2002).

20. Murr, L. E. et al. Friction-stir welding: Microstructural characterization. Mater. Res. Innov, 1 (no. 4), 211-223 (1998).

21. Bakavos, D. \& Prangnell, P. B. Mechanisms of joint and microstructure formation in high power ultrasonic spot welding 6111 aluminium automotive sheet. Mater. Sci. Eng. A, 527 (no. 23), 63206334 (2010).

22. Satpathy, M. P. \& Sahoo, S. K. Experimental and numerical studies on ultrasonic welding of dissimilar metals. Int. J. Adv. Manuf. Technol, 93, no. 5-8 (2017).

23. Ni, Z. L. \& Ye, F. X. Dissimilar Joining of Aluminum to Copper Using Ultrasonic Welding. Mater. Manuf. Process, 31 (no. 16), 2091-2100 (2016).

24. Zhang, Z., Wang, K., Li, J., Yu, Q. \& Cai, W. Investigation of Interfacial Layer for Ultrasonic Spot Welded Aluminum to Copper Joints. Sci. Rep, 7 (no. 1), 1-6 (2017).

25. Ni, Z. L. et al. Ultrasonic spot welding of aluminum to copper: a review. Int. J. Adv. Manuf. Technol, 107 (no. 1-2), 585-606 (2020).

26. Zhang, Y. et al. "Feasibility study of dissimilar joining of aluminum alloy 5052 to pure copper via thermo-compensated resistance spot welding," Mater. Des., vol. 106, no. June, pp. 235-246, 2016.

27. Hong, K. M. \& Shin, Y. C. Prospects of laser welding technology in the automotive industry: A review. J. Mater. Process. Technol, 245, 46-69 (2017). 
28. Mazumder, J. Laser Welding: State of the Art Review. JOM J. Miner. Met. Mater. Soc, 34 (no. 7), 1624 (1982).

29. Sun, Z. \& Ion, J. C. Laser welding of dissimilar metal combinations. J. Mater. Sci, 30 (no. 17), 42054214 (1995).

30. Xue, Z. et al. "Molten pool characterization of laser lap welded copper and aluminum," J. Phys. D. Appl. Phys., vol. 46, no. 49, 2013.

31. Fetzer, F., Jarwitz, M., Stritt, P., Weber, R. \& Graf, T. "Fine-tuned remote laser welding of aluminum to copper with local beam oscillation," Phys. Procedia, vol. 83, no. July 2017, pp. 455-462, 2016.

32. Dimatteo, V., Ascari, A. \& Fortunato, A. "Continuous laser welding with spatial beam oscillation of dissimilar thin sheet materials (Al-Cu and Cu-Al): Process optimization and characterization," J. Manuf. Process., vol. 44, no. June, pp. 158-165 2019.

33. Wang, X., Gu, C., Zheng, Y., Shen, Z. \& Liu, H. Laser shock welding of aluminum/aluminum and aluminum/copper plates. Mater. Des, 56, 26-30 (2014).

34. Lerra, F., Ascari, A. \& Fortunato, A. "The influence of laser pulse shape and separation distance on dissimilar welding of Al and Cu films," J. Manuf. Process., vol. 45, no. April, pp. 331-339 2019.

35. Murray, J. L. "The aluminium-copper," vol. 30, no. 5, 1985.

36. Wang, B. \& Gallais, L. A theoretical investigation of the laser damage threshold of metal multidielectric mirrors for high power ultrashort applications. Opt. Express, 21 (no. 12), 14698 (2013).

37. Nakajirna, H. T h e D i s c o v e ry and A c c e p t a n c e of th e K i rke n d a I I Effect: T h e R e s u I t of a Short R e s e a r c h C a r e e r. Jom, 49 (no. 6), 15-19 (1997).

38. Mao, A. et al. "The diffusion behaviors at the Cu-Al solid-liquid interface: A molecular dynamics study," Results Phys., vol. 16, no. 100, 2020.

\section{Figures}

a)

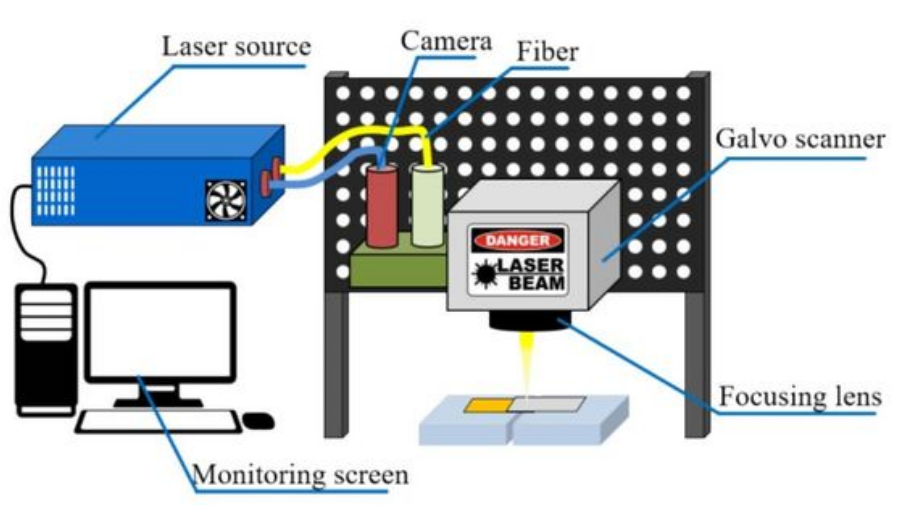

b)

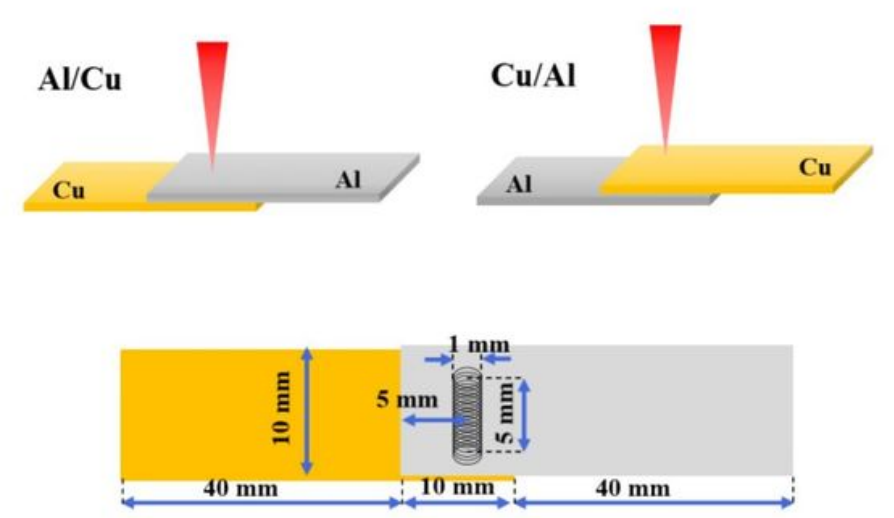

Figure 1 
a) Schematic of the experimental setup, b) Dissimilar welding configurations for the study.

\section{a)}
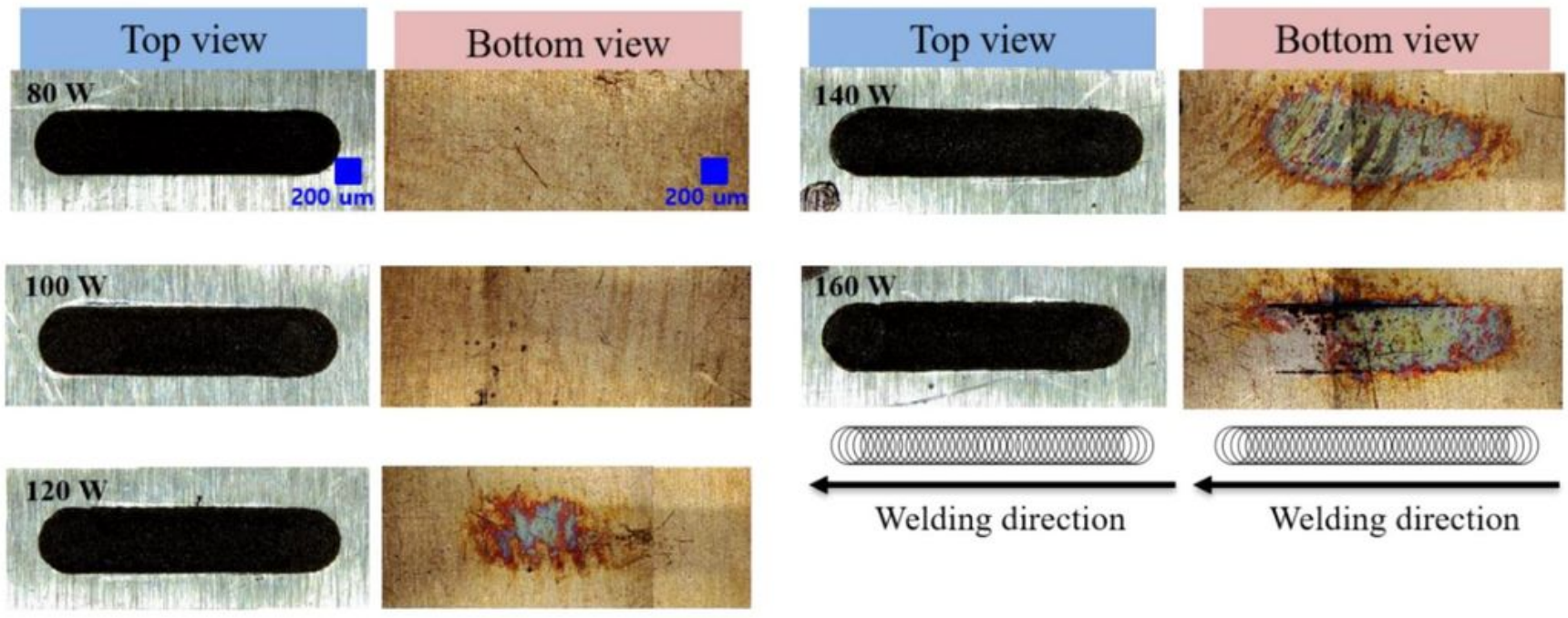

Welding direction
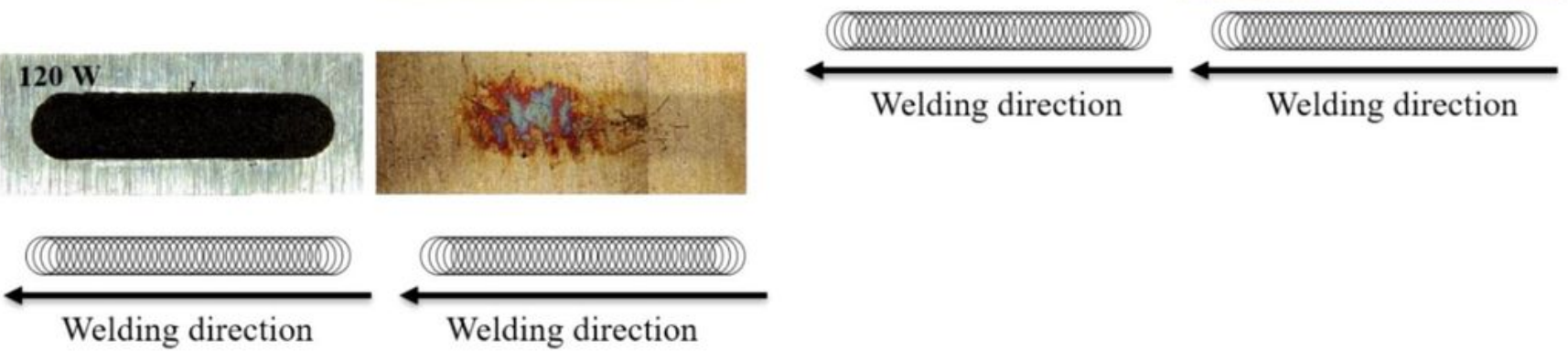

b)

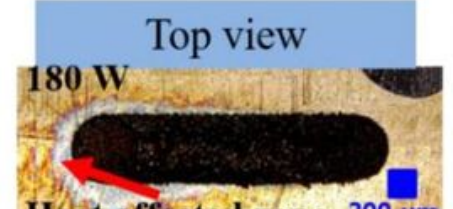

Heat affected zone $200 \mathrm{um}$
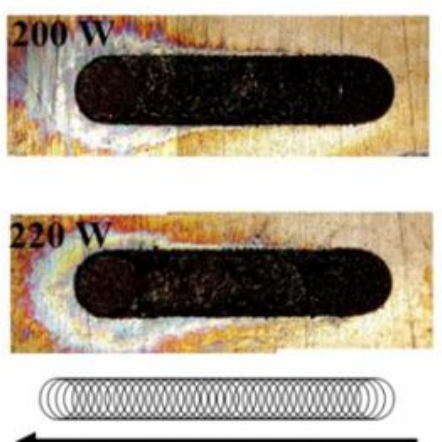

Welding direction
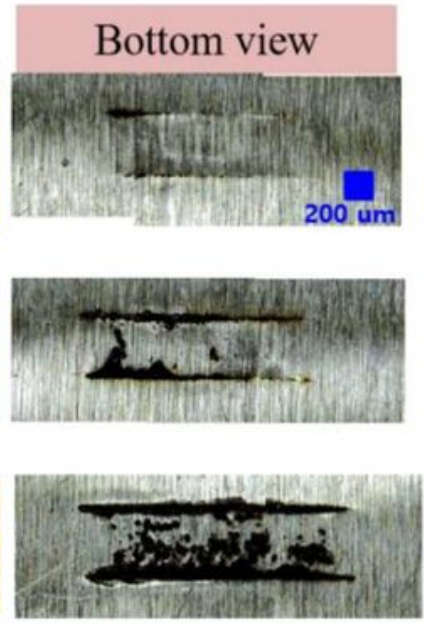

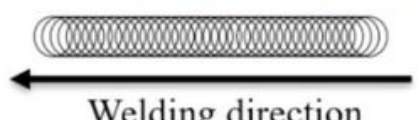

Welding direction
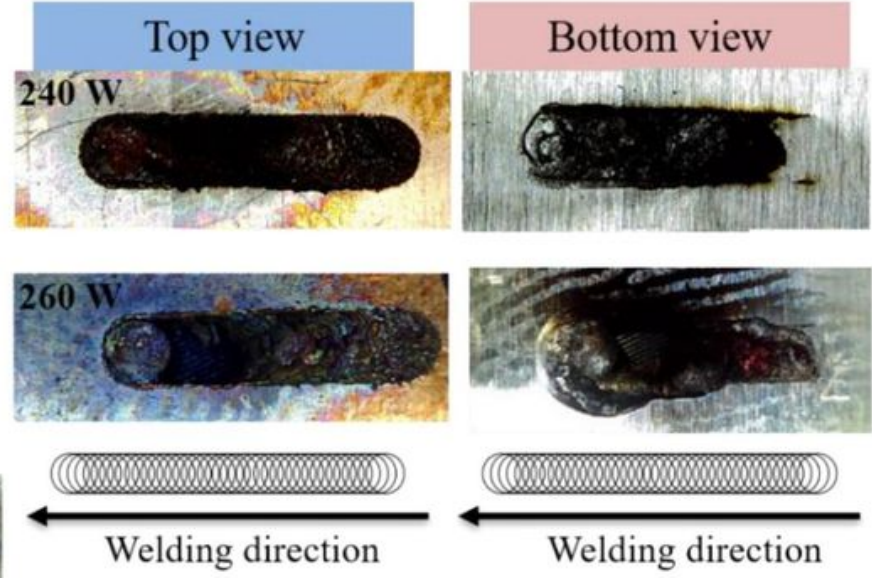

\section{Figure 2}

Top view and bottom view of the weld a) $\mathrm{Al} / \mathrm{Cu}, \mathrm{b}$ ) $\mathrm{Cu} / \mathrm{Al}$. 

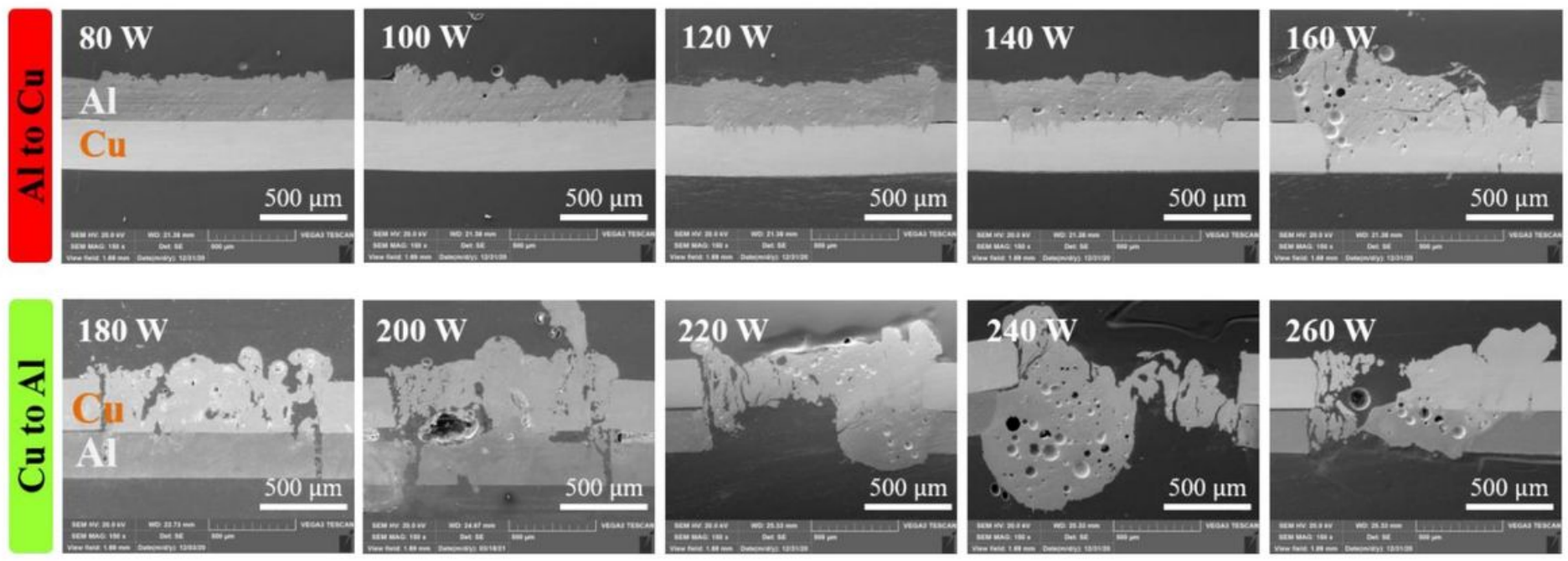

\section{Figure 3}

Cross-section views the weld of $\mathrm{Al} / \mathrm{Cu}$ and $\mathrm{Cu} / \mathrm{Al}$.
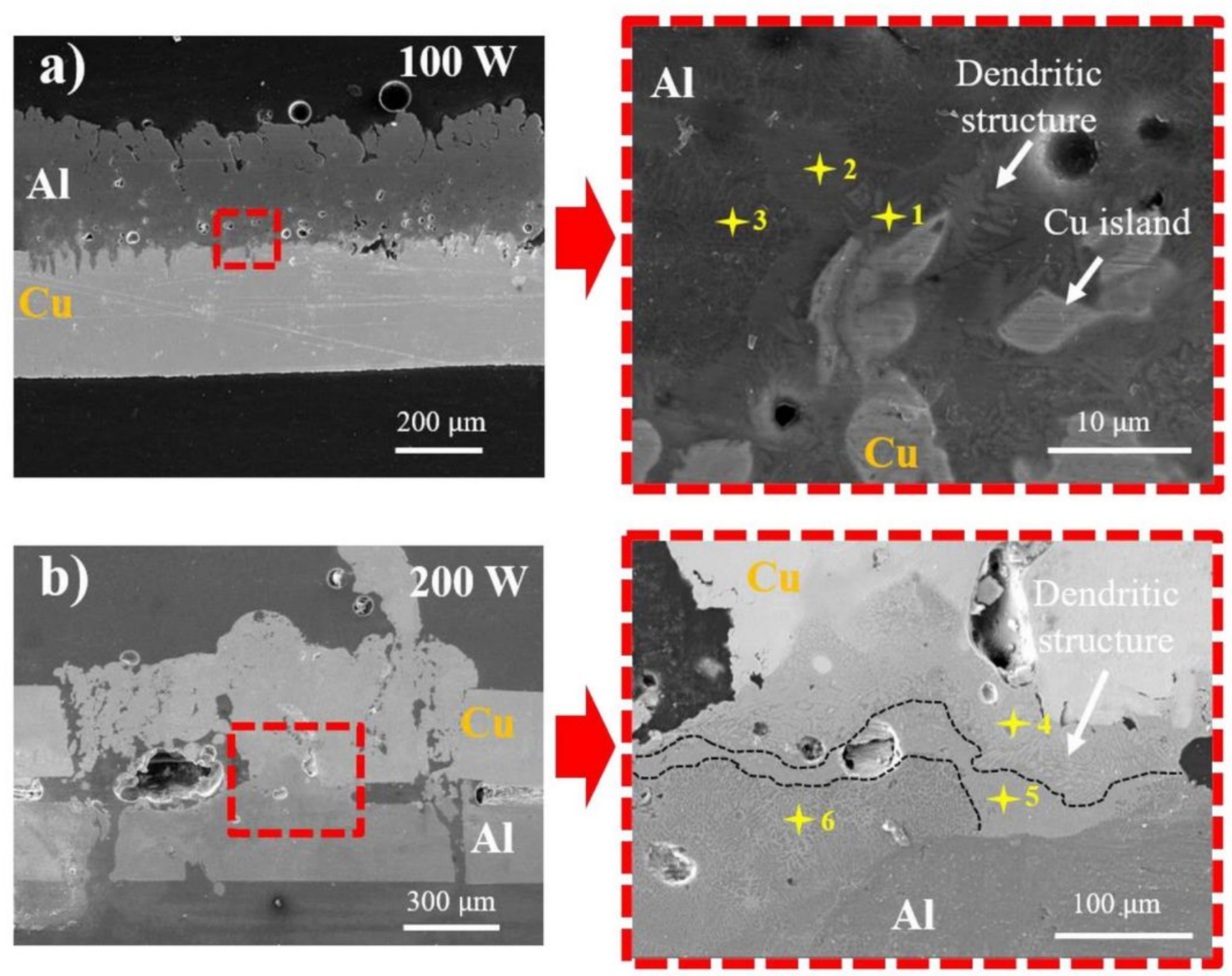
Figure 4

Microstructure at the interface of the weld a) $\mathrm{Al} / \mathrm{Cu}, \mathrm{b}) \mathrm{Cu} / \mathrm{Al}$.
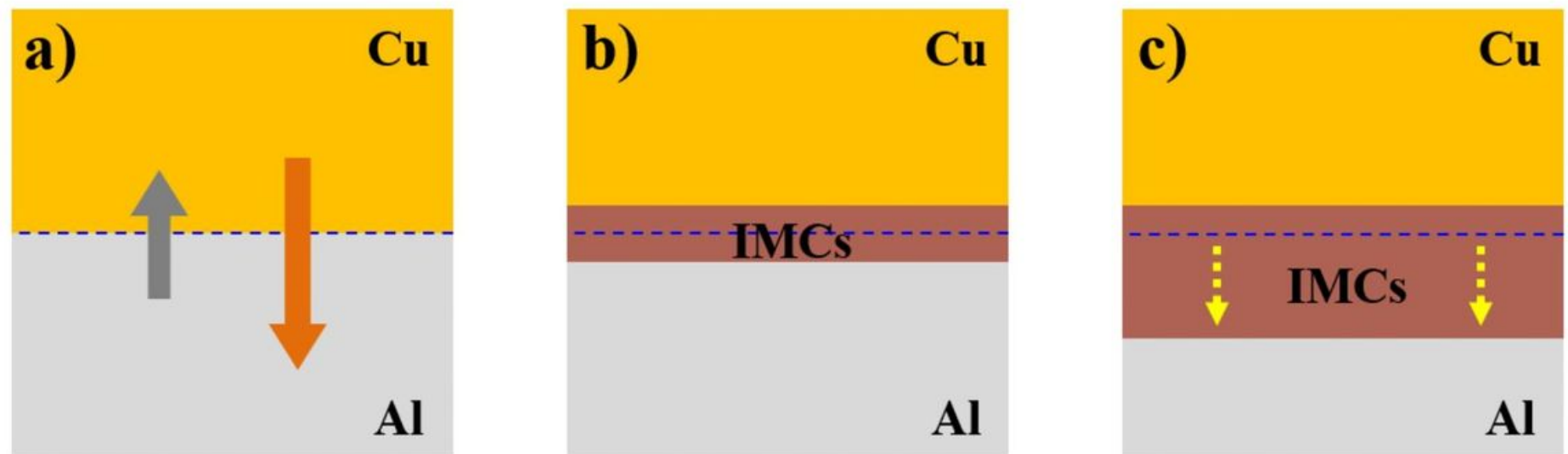

Figure 5

Kirkendall effect a) Diffusion of $\mathrm{Al}$ and $\mathrm{Cu}, \mathrm{b}$ ) IMCs formation, c) IMCs expansion.

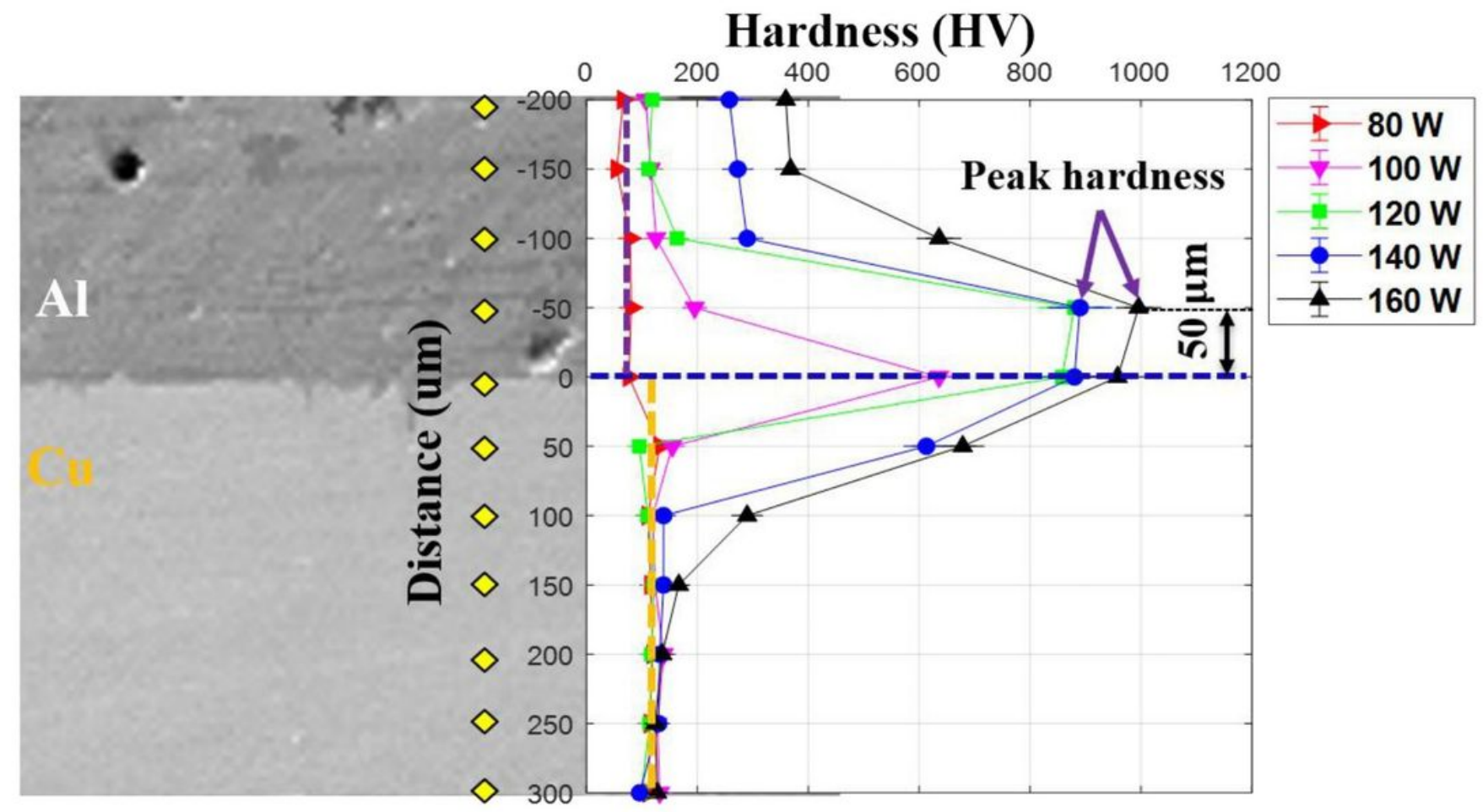

Figure 6

Hardness distribution in the weld of $\mathrm{Al} / \mathrm{Cu}$. 


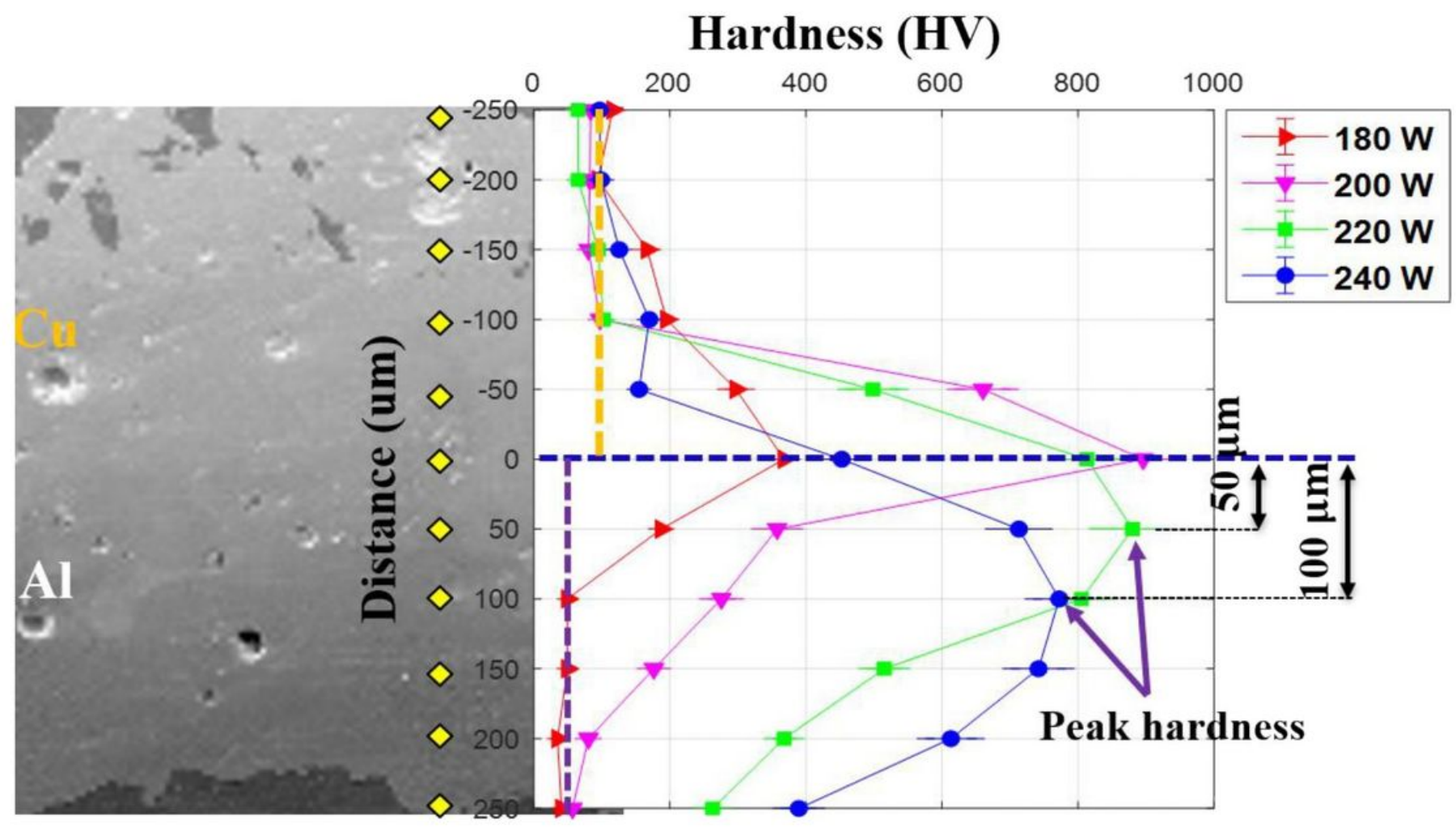

Figure 7

Hardness distribution in the weld of $\mathrm{Cu} / \mathrm{Al}$.

a)

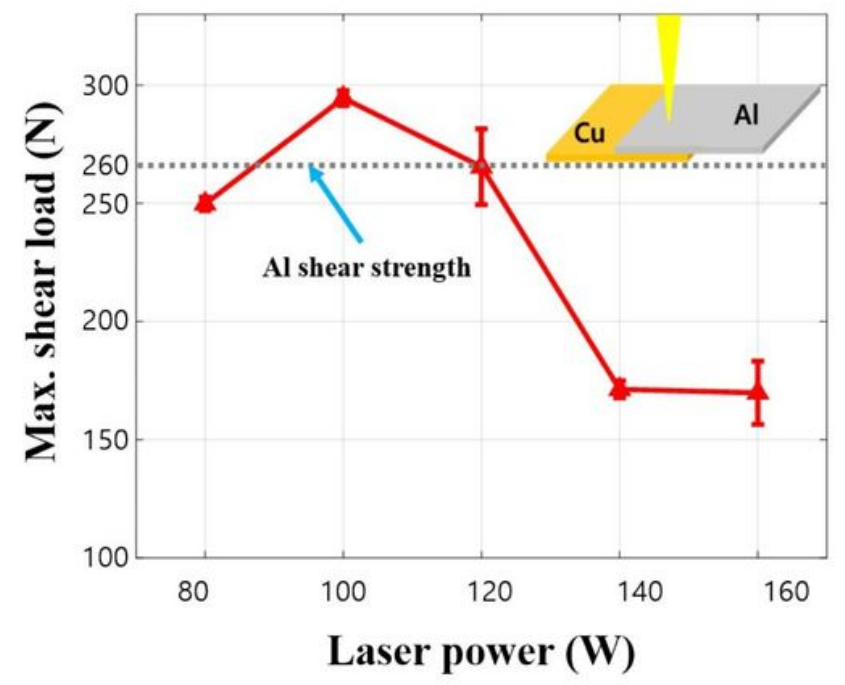

b)

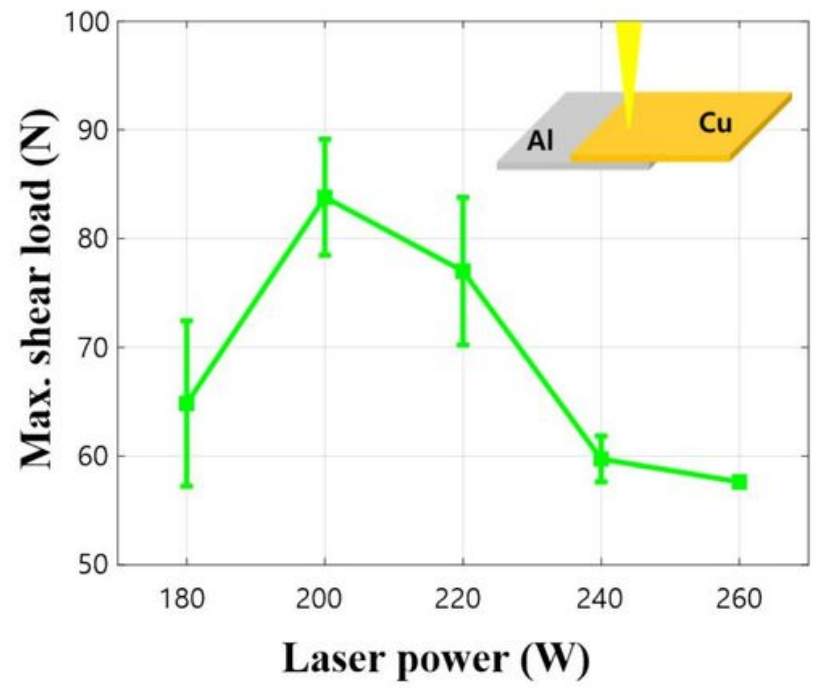

Figure 8 
Shear strength of the weld a) $\mathrm{Al} / \mathrm{Cu}, \mathrm{b}) \mathrm{Cu} / \mathrm{Al}$.
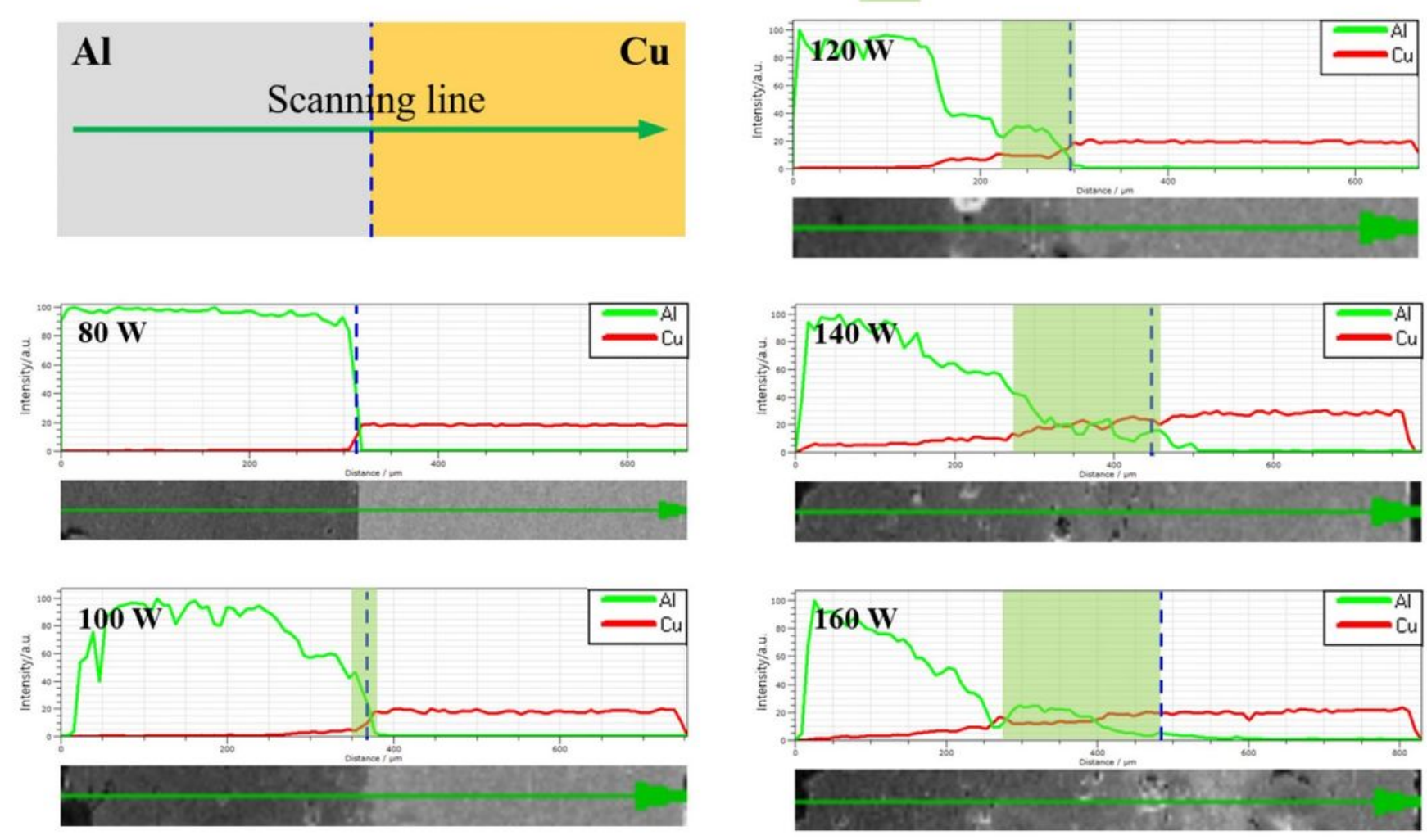

\section{Figure 9}

EDS line scan through the interface of the weld of $\mathrm{Al} / \mathrm{Cu}$.

a)

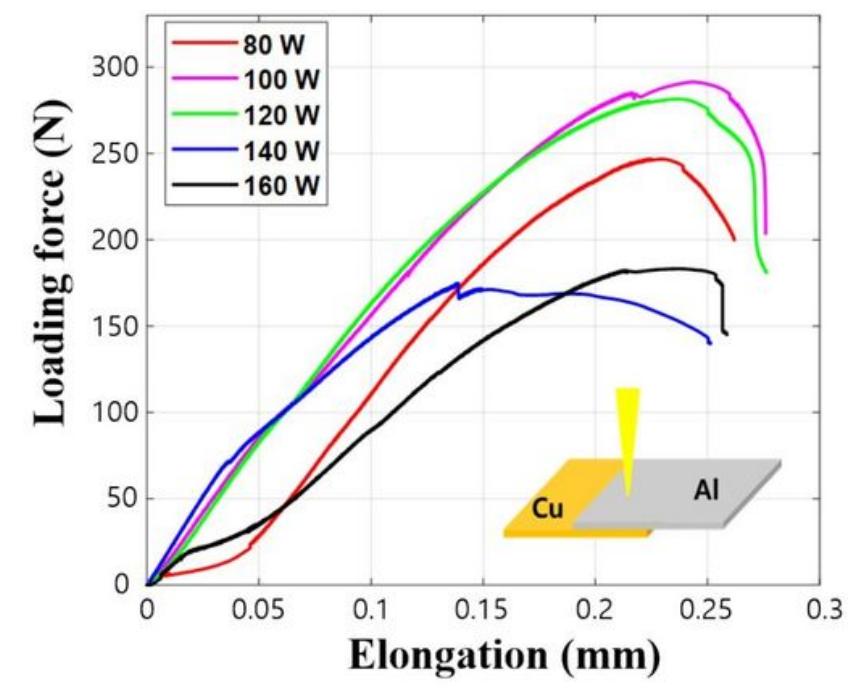

b)

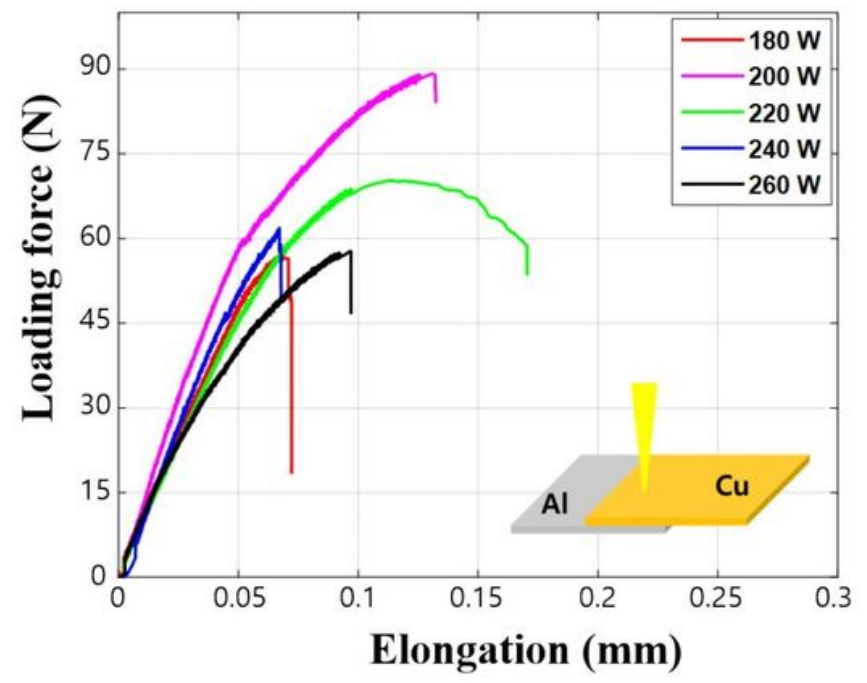

Figure 10 
Result of the shear strength test a) $\mathrm{Al} / \mathrm{Cu}, \mathrm{b}$ ) $\mathrm{Cu} / \mathrm{Al}$. 